\title{
Orchestrating Learning Using Adaptive Educational Designs in IMS Learning Design
}

Citation for published version (APA):

Gruber, M., Glahn, C., Specht, M., \& Koper, R. (2010). Orchestrating Learning Using Adaptive Educational Designs in IMS Learning Design. In M. Wolpers, P. A. Kirschner, M. Scheffel, S. Lindstaedt, \& V. Dimitrova (Eds.), Sustaining TEL: From Innovation to Learning and Practice: 5th European Conference on Technology Enhanced Learning, EC-TEL 2010, Barcelona, Spain, September 28 - October 1, 2010. Proceedings (Vol. 6383, pp. 123-138). Springer-Verlag Berlin Heidelberg. https://doi.org/10.1007/978-3-642-16020-2_9

\section{DOI:}

10.1007/978-3-642-16020-2_9

Document status and date:

Published: 01/01/2010

Document Version:

Publisher's PDF, also known as Version of record

Please check the document version of this publication:

- A submitted manuscript is the version of the article upon submission and before peer-review. There can be important differences between the submitted version and the official published version of record. People interested in the research are advised to contact the author for the final version of the publication, or visit the DOI to the publisher's website.

- The final author version and the galley proof are versions of the publication after peer review.

- The final published version features the final layout of the paper including the volume, issue and page numbers.

Link to publication

\section{General rights}

Copyright and moral rights for the publications made accessible in the public portal are retained by the authors and/or other copyright owners and it is a condition of accessing publications that users recognise and abide by the legal requirements associated with these rights.

- Users may download and print one copy of any publication from the public portal for the purpose of private study or research.

- You may not further distribute the material or use it for any profit-making activity or commercial gain

- You may freely distribute the URL identifying the publication in the public portal.

If the publication is distributed under the terms of Article 25fa of the Dutch Copyright Act, indicated by the "Taverne" license above, please follow below link for the End User Agreement:

https://www.ou.nl/taverne-agreement

Take down policy

If you believe that this document breaches copyright please contact us at:

pure-support@ou.nl

providing details and we will investigate your claim.

Downloaded from https://research.ou.nl/ on date: 26 Apr. 2023 


\title{
Orchestrating Learning using Adaptive Educational Designs in IMS Learning Design
}

\author{
Marion R. Gruber, Christian Glahn, Marcus Specht \& Rob Koper \\ CELSTEC, Open University in The Netherlands, \\ Valkenburgerweg 177, 6419AT Heerlen, The Netherlands \\ \{marion.gruber, christian.glahn, marcus.specht, rob.koper\}@ou.nl
}

\begin{abstract}
IMS Learning Design (IMS LD) is an open specification to support interoperability of advanced educational designs for a wide range of technology-enhanced learning solutions and other units of learning. This paper analyses approaches to model personalised learning experiences with and without explicit adaptive features in IMS LD. The paper has two main parts. The first part analyses the relation between orchestrating learning and IMS LD's semantic features. The second part compares modelling strategies for educational designs for personalised learning in non-collaborative learning units using IMS LD Level A and IMS LD Level B features. The analysis is based on two worked-out IMS LD units. The paper concludes with a comparison of the two modelling approaches and addresses gaps when integrating adaptation concepts at the levels of the specification.
\end{abstract}

Keywords: adaptation, IMS Learning Design, educational design, personalization, orchestrating learning

\section{Introduction}

IMS Learning Design (IMS LD) is an open specification to support interoperability of advanced educational designs for a wide range of technology-enhanced learning solutions and other units of learning (UoL). The specification has been released in 2003 [1] and has been subject to a broad scientific discussion [2, 3]. Recent developments in the context of the TENCompetence project [4] have led to an improved set of tools and services for modelling and deploying educational designs in IMS LD [5] These developments extend the perspective on the capabilities of IMS LD and allow a better analysis of related educational design approaches.

IMS LD provides a semantic framework to formally express educational designs and to model learning processes with innovative technologies. Through scaffolding key parameters of learning IMS LD provides a framework for orchestrating learning processes and personalising competence development. The emphasis on modelling learning processes makes IMS LD a potentially useful framework for tackling the research challenges related to orchestrating learning that have been identified by the STELLAR project [6]. However, only a few research publications have addressed 
personalisation and adaptation with IMS LD in the past years [7, 8, 9]. Related research focused entirely on semantic structures of IMS LD for conditional modelling. This focus is to narrow for reflecting the full potential of IMS LD's semantic framework for orchestrating learning.

This paper analyses the application of the conceptual structure of IMS LD for modelling personalised learning experiences. This analysis is based on the recent discussion on personalisation and adaptation in technology-enhanced learning using IMS LD, which is reflected in the background section. It is followed by a section that identifies the research question for this paper and identifies two underlying analytical problems: the relation of IMS LD to orchestrating learning and practical approaches and limitations of IMS LD for modelling orchestration scripts. The section orchestrating learning analyses the dimensions of orchestrating learning based on selected literature. It is followed by the analysis of what semantic features IMS LD refer to the different dimensions. Based on these insights two variations of a UoL analyse the modelling strategies at the different complexity levels of IMS LD. Finally, this paper compares the different approaches and discusses gaps that were identified with respect to the orchestration dimensions.

\section{Background}

Personalisation is increasingly important in technology-enhanced learning. However, personalised learning is not unambiguous. Two general viewpoints on personalisation can be identified. The first viewpoint defines personalised learning as individualised and tailored educational experiences [10]. The personal dimension in this viewpoint is directed towards facilitated educational processes that are unique to a learner. The second viewpoint emphasises the personal relevancy and involvement of individuals in learning processes [11]. From this perspective, personalised learning refers to those processes that support learners to take responsibility and control over their learning and enable them to reflect on the learning on a meta-cognitive level.

The two perspectives on personalisation are not mutually exclusive: learner-controlled learning processes may lead to unique learning experiences and automatically adapted educational environments may support deeper learning experiences that allow learners to feel more responsible for their learning. However, learner control can be provided in mass education and fully tailored educational processes can be provided without leaving any control to the learner.

Dron [12] argues that personalised learning does not require that learners have full control over their learning, but it requires that some control is left to the learners. Based on this premise, educational designs for personalised learning refer to those educational designs that enable learners to control and regulate their learning based on predefined tasks [13]. Educational designs are adaptive if their task arrangements can reflect the learners' control decisions. Such designs are orchestration scripts for the educational practice. Orchestrating refers to educational practices that organise and arrange learning activities and learning environments to guide learners through learning processes. In this sense the orchestration refers to control and regulation mechanisms for framing parameters of learning processes [14]. 
From an adaptive educational hypermedia perspective Brusilovsky [15] distinguishes between adaptive presentation and adaptive navigation support to categorise the different approaches for personalising and adapting information. Additionally, a third category has to be included: adaptive sequencing. Although adaptive sequencing is sometimes categorised under adaptive navigation support, adaptive sequencing focuses on the arrangement of processes whereas Brusilovsky's definitions of adaptive navigation support focuses on navigational features at information level. At this level orchestration scripts define the rules for using and combining the different approaches.

IMS LD provides a generic and flexible language to model educational designs in a machine-readable format. As an open specification it allows to prepare orchestration scripts for technology-enhanced learning. One of the requirements for IMS LD was that the language can describe personalization aspects within an educational design, "so that the content and activities within a unit of learning can be adapted based on the preferences, portfolio, pre-knowledge, educational needs and situational circumstances of the participants in educational processes. In addition, it must allow the designer, when desired, to pass control over the adaptation process to the learner, a staff member and/or the computer." [16, p. 14]

IMS LD has three complexity levels [17].

1. IMS LD Level A provides the core elements for creating educational designs. Conditional rules for controlling the learning process are limited to basic aspects of sequencing educational processes.

2. IMS LD Level B adds complex conditional elements that allow learner modelling, fine grained process control, and offers personalisation and adaptation features.

3. IMS LD Level $\mathrm{C}$ extends the process model by a notification feature that allows to model event-based processes.

Previous research on modelling adaptive educational designs with IMS LD has analysed approaches for modelling units of learning with basic adaptive and personalisation features. These approaches have been primarily guided by usermodelling and adaptation concepts from an adaptive hypermedia research perspective that is discussed by Aroyo et al. [10].

Paramythis and Loidl-Reisinger [18] reflect personalisation at the level of properties and conditions. The authors analyse these features for authoring fully dynamic adaptive processes. The authors conclude that IMS LD is most appropriate to transfer snapshots of adaptation logic between systems. Berlanga and Garcia [7] focus on content adaptation using meta-data fragments to define templates for learning resources. The arrangement of the resources is entirely based on the sequencing features of IMS LD. Instead of utilizing higher order control features of IMS LD for adaptation, the authors propose to store rules for adaptation separated from the educational design. Specht and Burgos [9] analyse what types of adaptation can be modelled using the language features of IMS LD. Their analysis includes partial usermodelling using properties and calculations as well as the application of conditions for adapting aspects of the educational design to the needs of the learner. The authors identify that IMS LD provides strong support for modelling adaptive sequencing, adaptive content presentation, and adaptive navigation support.

Van Rosmalen et al. [19] analyse the role of IMS LD in the lifecycle of adaptive elearning courses. The authors propose that the educational design carries only general 
guidelines for personalising the learning experience. External modules of a runtime environment handle all other types of adaptation, such as recommendations or link adaptation. The authors describe the interrelation between the different system components for adaptive e-learning and discuss briefly the role of properties and conditions as connectors for personalisation and adaptation.

The semantic of IMS LD is based on an orchestration metaphor [16]. This metaphor means an abstraction from specific technologies, resources, tools, and services. This implies the emphasis of arranging and managing the communication between learners among each other and with their environment. Therefore, IMS LD supports designers to create orchestration scripts using a machine-readable notation for supporting learning processes under different technical conditions. Besides the commonly promoted property-condition-based approach of adaptation for personalisation that uses IMS LD Level B concepts, IMS LD offers alternatives for integrating personalisation facets into educational designs.

IMS LD is a modelling language for educational designs. Although its semantic structures share some characteristics with programming languages, several aspects that would be required for providing a full programming language were intentionally excluded from the specification. Consequently, it is not possible to model low level adaptation algorithms entirely in IMS LD. This restriction implies that some aspects of adaptive systems lie outside the scope of IMS LD. This is particularly the case for user-modelling concepts that reflect learner history at great detail. Low-level computational aspects are part of associated services. This approach is now researched in the GRAPPLE project in which external user-modelling services work together with authoring and run-time components to implement educational designs $[20,21]$. With IMS LD Level B it is possible to integrate such services through so called global properties through which a service can expose certain information to the educational design [22].

\section{Research question}

One aspect of orchestration scripts is to describe personalisation options. In this context, personalisation means dynamic adaptation of the learning support based on the learners' needs or previous learning experiences. Motivated by the related research objective of the GRAPPLE project to identify approaches and possible gaps related to modelling units of learning with adaptive features in IMS LD [23], this paper analyses personalisation concepts that are inherent in the IMS LD semantics. Consequently, the following research question provides the underpinning for this analysis.

How to use IMS LD to model concepts for modelling personalisation in the orchestration of educational designs for technology-enhanced learning?

This research question implies two aspects for the analysis.

1. It is required to understand how the semantics of IMS LD represent the different aspects of orchestrating learning and personalisation. The analysis of this aspect addresses the formal representation of orchestration scripts with the semantic concepts of IMS LD. 
2. It is necessary to analyse how IMS LD concepts reflect personalisation in educational designs. This aspect addresses modelling concepts for representing variations of a generic educational approach.

By understanding the relation between the different concepts of modelling orchestrating scripts with their practical implications, it is possible to identify the gaps in the modelling concepts as well as concepts that fall outside the scope of the specification.

\section{Orchestrating learning}

Dillenbourg [14] identifies three dimensions that are involved in orchestration. Firstly, the interplay of learning activities at different social planes. The planes are bound to the social connectedness of learners on the activity level and can include the individual, collaborative, collective (class wide) activities. Secondly, the timing of an educational script. Timing refers to the interrelation of the learning activities and the transitions from one activity to another. Finally, the focus on the learning process. Focus refers to emphasizing or hiding aspects of the learning objective in order to guide the students' attention. Integrating these dimensions allows teachers to manage the available environment for learning.

Orchestrating learning is closely related to educational design. According to Goodyear and Yang [13] educational design "is largely a matter of thinking about good learning tasks (good things for learners to do) and about the physical and human resources that can help learners to succeed with such tasks." [13: p169] When analyzing educational designs it is required to distinguish between learning outcomes, learning activities, and learning tasks. "Learning outcomes are the durable, intended, and unintended cognitive, affective, and psychomotor consequences of the learner's activity (mental or physical)." [13: p169] These outcomes are the result of what the learner does. In other words, learning outcomes are the direct consequence of the activity of a learner. According to Goodyear and Yang, learning activities are based on the learner's interpretation of the requirements of learning tasks. Teachers or instructional designers typically define learning tasks.

Van Merriënboer, Clark, and de Croock [24] structure the educational design process into four interrelated components: learning tasks, supportive information, just-in-time information, and part-task practice. Learning tasks are provided to learners in order to stimulate whole-task experiences for constructing knowledge (schema and rules). Supportive information is supportive with respect to the learning tasks. It bridges between learners' prior knowledge and the learning task. Just-in-time information refers to procedural rules of the educational design and the related information for communicating these rules to learners. Part-task practice items "are provided to learners in order to promote rule automation for selected recurrent aspects of the whole complex skill" [24: p43]. Educational design processes rely on aligning these components for generating coherent learning experiences that lead to higher transfer performance then designs that do not take all components into account.

While educational design is indirect to the learning situation, orchestrating learning implies also the direct management of performing learning tasks during runtime. 
From this viewpoint orchestrating learning includes the personalisation and the adaptation of learning tasks, because personalisation and adaptation refer to management decisions related to dynamic task arrangements in a learning environment. However, educational design and orchestrating learning go beyond defining rules for learning. Both concepts build on three pillars: learning tasks (and sub-tasks), learning environments, and procedural rules. Orchestrating learning crucially depends on the coordination of the relations between these pillars.

Koper and Specht [4] argue that related coordination problems can be identified at different levels of complexity of the learning environment. New tools and services can enrich the learning environment in ways that meet the learning needs of lifelong learners. Furthermore, the authors emphasize the relation between services and roles in learner communities at the different levels.

Based on the research on educational design, orchestrating learning refers to the coordination and the alignment of four dimensions.

- The roles that are involved in the educational activities and the interplay of the different social planes [14].

- The learning tasks include the main learning tasks [13], supportive tasks, and part tasks [24].

- The learning environment includes all kinds of services, knowledge resources [4], just-in-time and supportive information [24].

- The rules and directives for the educational process include the timing and the educational focus [14].

\section{Modelling concepts of IMS LD}

The four dimensions of orchestrating learning are directly supported by the semantic structure of IMS LD across all complexity levels of the specification (see Table 1).

IMS LD provides two basic role types that are involved in a UoL: the learner role and the teacher role. The learner role refers to those participants of a UoL that follow the educational design in order to meet the learning objectives. The teacher role refers to those participants in a UoL that facilitate and moderate the educational process and support the learners. Based on these basic types a designer can model sub-roles for specific aspects of an educational design. One important feature of IMS LD's subroles is that they can be used for grouping.

Learning tasks are called "learning activities" in the IMS LD terminology. Based on the separation of learning and supporting roles, IMS LD provides the concept of "support activities". Each learning activity has a description and a completion rule. Additionally, learning activities may have prerequisites and learning objectives defined. The activity descriptions, prerequisites, and objectives provide information that helps the participants to interpret the activity and act according to the set expectations. The completion rule defines when a learning activity has to be considered as completed. A learning activity can either be infinite or completed by user choice, based on a time limit, or (for IMS LD Level B and C) if a predefined condition is met. For IMS LD Level B and C it is important to understand that the completion state of an activity is terminal. In other words, "completing" an activity is 
like a school degree: once it has been achieved, it cannot be repeated. At IMS LD Level A this constraint is not relevant because at this level it is only possible to define linear, loop free educational designs.

The concept of the learning environment is directly reflected in IMS LD. The learning environment is a concept for bundling resources, tools, and services in the terminology of IMS LD. Through this concept it is possible to model arrangements of resources and tools that can be used across learning activities. For example, if an environment contains a discussion forum that is linked to different learning activities, the learners will find the same postings that were posted in an earlier activity, in a later learning activity. If the discussion forum service is used in different environments, it means that different discussions are planned.

IMS LD provides several structures and semantic concepts for defining rules and directives for structuring the educational process itself. IMS LD Level A allows orchestration of learning activities, roles, and environments at the level of the educational design's method and at the level of activity-structures.

Activity-structures are constructs to arrange learning activities into more complex structures. From the design perspective, activity-structures are handled the same way as learning activities. IMS LD offers two types of structures: activity sequences and selections. Activity sequences define that the learning activities have to be followed in the order given in the activity-structure. Selections allow educational designers to model in a way that learners can choose one or more activities. For selections a designer can specify how many learning activities have to be selected from the structure before the structure is considered as completed. Through nesting of learning activities and activity-structures, designers can model basic processes.

Modelling personalization features using activity-structures is independent from the role that will perform the activity. Thus, this approach emphasizes the relation between learning activities. Modelling directives with activity structures commonly starts with conceptualising the process from the macro processes down to the individual learning activities. The initial step of modelling activity-structures is based on the decision of the initial step of processing the activity-structure.

In IMS LD the method may include more than one approach to reach the learning goal of a UoL. In the IMS LD terminology these approaches are called 'plays'. Each play connects the learning activities with a role that is expected to perform this activity in the current play. Different plays can refer to the same learning activities but assign them to different roles. By choosing alternative roles at the beginning of a UoL, learners can choose between different approaches. The actual association of learning activities to roles is done in acts. All plays in IMS LD have at least one act. Acts serve as synchronisation points for all participants in a play. This means that if an act is completed, it is completed for all participants in the same play.

The modelling strategy for role-play-based personalization requires for each play of the UoL a primary learner role. All learning activities within the play will be assigned to this role. In more complex scenarios in which learners are assigned to new roles in the process of the play at least the initial learning activities in this play have to be assigned to the primary role. Furthermore, it is necessary that also the subsequentially assigned roles are not connected to activities in multiple plays, otherwise the activities of the different play may appear out of the context to the learner. During the modelling of such a UoL, learners can either choose a role for their preferred 
approach or they are assigned to different roles. For example, the default of the CopperCore runtime engine is that learners can choose for themselves.

IMS LD Level $\mathrm{B}$ adds properties and conditions through which designers can include information models and logical constraints into their educational designs. The approach is related to generic user modelling [25]. Properties provide an abstraction for recording, representing, provisioning, and evaluating characteristics of learners and groups and their behaviour. Conditions allow expressing assumptions and generalising one or more types of learner characteristics in relation to the UoL. Three types of information models can be distinguished in IMS LD: the course information model, the group information model, and the user information model.

The course information model is based on generic properties. Within one instance of a UoL the value of these properties is shared with all participants. These properties can be used to model course wide contexts. The group information model is based on role-properties. The information of these properties is shared with all members of the same role - or if a role can have multiple instances within a UoL the information is shared with all members of the same instance of the role. This restriction allows to model group activity within a UoL. The user information model is based on personalproperties. Personal-properties refer to information that is different for every participant. These information models can be used to define rules for the orchestration. In IMS LD these rules are expressed through if-then statements. The conditional part of these statements refers to the property models or to a small number of process states for the UoL. Each condition has a consequence that is defined in the "then"-clause. An instructional designer can hide and show different parts of the educational design or set the value of properties. Hiding and showing includes learning activities, learning environments, plays, and HTML content fragments. Furthermore, authors can trigger notifications based on conditions on IMS LD Level C.

Table 1: Relation between orchestration dimensions and IMS LD concepts

\begin{tabular}{ll}
\hline Dimensions of Orchestrating Learning & IMS LD Semantic Concepts \\
\hline Learning tasks & Learning activity \\
& Support activity \\
Learning environment & Environment \\
Orchestration rules & Activity-structure \\
& Play \\
& Act \\
& Role-part \\
& Personal-property $^{\mathrm{a}}$ \\
& Role-property $^{\mathrm{a}}$ \\
& Property $^{\mathrm{a}}$ \\
& Condition $^{\mathrm{a}}$ \\
& Notification $^{\mathrm{b}}$ \\
& Learner role \\
& Teacher role \\
& (inherited roles) \\
\hline
\end{tabular}




\section{Practical aspects of modelling personalised learning with IMS LD}

The previous section analysed the relation between the dimensions of orchestrating learning and the semantic concepts of IMS LD. This section analyses how IMS LD concepts reflect personalisation in educational designs and orchestration scripts. This analysis is based on two variations of the UoL "Modern Architecture: Skyscrapers and Residential Homes" [26, 27]. This UoL has been developed on top of MACE Metadata Services [28]. The UoL provides a self-study course and does not include collaboration features.

The first variation of the UoL is entirely modelled on IMS LD Level A and illustrates personalisation concepts and service integration. This UoL is based on the MACE IMS LD Template [29]. The second variation of the UoL is modelled on IMS LD Level B and models an adaptive and personalised approach to the learning objectives of the UoL. Both variations are based on almost the same learning activities. This allows comparing differences in the modelling approaches for modelling personalised learning using the available concepts of IMS LD. Both UoLs were modelled with the ReCourse Editor [30] and tested with the SLED/CopperCore 3.4 runtime [31].

\section{Common outline of the Unit "Modern Architecture: Skyscrapers and Residential Homes"}

The UoL "Modern Architecture: Skyscrapers and Residential Homes" focuses on modern architecture based on two construction styles - skyscrapers and residential homes. The selected buildings for representing the construction styles are from three architects: Frank L. Wright, Frank O. Gehry, and Ludwig Mies van der Rohe. For each architect one building of each construction style is discussed in the UoL. This leads to three tracks for the educational design. Every track brings different objects from one architect together.

The core design is based on a general introduction, followed by introductions into the main areas (skyscrapers and residential homes), a user selectable sequence of the architect tracks, and a final reflection activity.

Furthermore, the educational design is based on five learning activities that describe and define what the learner should do. The activities also require the learning process and help the learner to organise learning individually. The following learning activities are in both educational designs integrated: search, explore, study, summarise, and reflect.

Every learning activity has a provided learning environment in which all objects and tools for learning are available. MACE offers a set of various possibilities to utilise the MACE portal with its tools and services in education. MACE stands for 'Metadata for Architectural Contents in Europe'. In this project an Internet-based information system was developed that links up major international architectural archives with data records about completed and presently planned construction projects.

The MACE portal offers several possibilities to search and browse content: 'Filtered Search', 'Browse by Classification', 'Browse by Competence', 'Browse by 
Location', and 'Social Search'. But it also allocates various contents and real world objects from all over the world. Through these functions learners can search architectural content from different repositories, using metadata for filtering, visualizing results, or defining search parameters. MACE allows to navigate metadata in order to access content repositories through a toolset for a critical mass of digital content for learning with semantically well-defined metadata and associated formal descriptions that give meaning to metadata. Metadata enables new forms of explorative learning, integration of rich content in formal educational processes, or self-directed learning for ongoing professional development. These tools enable the application of quality-content-based services and are integrated in the learning environment of the UoL "Modern Architecture: Skyscrapers and Residential Homes" as well as related contents from MACE additionally to other online resources like documents, books or websites.

The learning objectives in this UoL are based on the standardised definition of architecture competences [32, 33]. The core targets for "Modern Architecture: Skyscrapers and Residential Homes" are

- Obtain adequate knowledge of the history and theories of architecture and the related arts, technologies and human sciences;

- Understand the relationship between people and buildings, and between buildings and their environment, and the need to relate buildings and the spaces between them to human needs and scale;

- Understand the profession of architecture and the role of the architect in society, in particular in preparing briefs that take account of social factors;

- Understand the structural design, constructional and engineering problems associated with building design.

These learning objectives define the learning outcomes that a learner should achieve through the UoL.

\section{Orchestrating learning on IMS LD Level A}

IMS LD Level A structures are commonly not considered for personalization and adaptation. This does not mean that it is completely impossible to consider personalisation for an educational design. However, the available semantic structures at this level restrict the possible personalization to adaptive sequencing.

Three semantic features of IMS LD can be used at this level to define orchestration rules. These features are roles, plays, and activity-structures. In the terminology of IMS LD roles group participants that do different things or similar things differently than participants of other roles. Therefore, a separate learner role is required for each approach to reach a learning goal. Plays define the educational approach of a UoL. IMS LD does not limit the number of plays in a UoL. Each play refers to a distinct approach to meet the learning objectives. This means that typically learners will not change the play they have chosen or were assigned to. While plays are rather fundamental differences in the educational approach, activity-structures offer smallscale variations within one approach. This allows to model different pathways through a framing play. In real world scenarios, the two modelling approaches will be used in combination, as it is discussed below. 
For the UoL "Modern Architecture: Skyscrapers and Residential Homes" all plays have a single act. This means that synchronization of the participants of an instance of this UoL is neither required nor possible.

The UoL consists of two plays that offer different pathways through the learning activities, while these plays are based on the same learning activities. The only difference between the approaches is the arrangement of the learning activities in activity-structures of the two plays.

The first play provides an architect-centred approach, in which the learners are guided through the curriculum based on the works of a single architect at the time once they have passed the introduction phase. Once all learning activities have been completed, the learner enters a reflection and assessment phase. Because of the sequential structure of this approach it is primarily based on a sequence structure. For the different sub-topics a learner can choose the learning activity or track to start with. In order to complete the activity-structures the learner has to perform all activities and follow all tracks within the structure.

The second play offers a building-type-centred approach that focuses on comparing similar buildings before learning more about the architects who designed the buildings. The reflection activities are aligned with the related topics. At the beginning of this approach, learners can choose the focus to start with. Therefore, the primary activity-structure is based on a selection of one out of two possible tracks.

The sequences of introducing, intensifying, and reflecting on a type of building can be found in both tracks in different arrangements within the two tracks of the second play. Therefore, these sequences were modelled as individual activity structures that can be reused in different arrangements. Typically, instructional designers define these structures in the interface of an IMS LD editor and do not bother about the underlying XML data format.

Because sequence and selection activity-structures depend on learning activities that are completed, the completion condition of all learning activities has been set to "user-choice". This allows the learners to indicate if they have finished a given activity and wish to proceed on their learning path.

\section{Orchestrating learning on IMS LD Level B}

The options for modelling variations and personalisation of learning paths are limited in IMS LD Level A. IMS LD Level B introduces basic user-, group-, and conceptmodelling features through properties and conditions. While these concepts provide more flexibility for including personalization and adaptive behaviour, it is also necessary to follow a different approach to model the adaptive behaviour.

The semantic features that are used at this level are plays, roles, properties, conditions, show, and hide. The modelling approach using plays and roles is the same as in IMS LD Level A. Instead of using different roles to define different learning approaches, personal properties are used to identify the learner's state within the process of the UoL. This allows the modelling of fine-grained personalized variations inside a play. The personalization is achieved through conditions. Conditions provide the underpinning for orchestrating a UoL and allow the modelling of more complex educational approaches. This includes didactical loops, content adaptation, 
conditional availability of learning activities, and interactive process control. The "show" and "hide" elements indicate if a learning activity should be made available or hidden for the learner.

For maximizing the flexibility for personalization and adaptation, properties and conditions replace activity-structures. Avoiding activity-structures for Level B UoLs allows easier integration of new adaptation and personalization rules. Furthermore, it is useful to mark all learning activities as "infinite" because of the terminal definition of the completion state in IMS LD. This step is required if learners are expected to repeat certain learning activities. Furthermore, only the initial learning activity is initially available, the visibility of all other activities is set as hidden.

The IMS LD Level B variation of the "Modern Architecture: Skyscrapers and Residential Homes" integrates the architect-track, the skyscraper-track, and the residential-home-track into a single play. The learners are allowed to freely work through the different tracks depending on their interests. After the general introduction of the UoL, the learner can set a preference of a topic to begin with. This preference can be either "skyscrapers" or "residential homes". This choice activates the introduction to the topic and as soon as the learner feels comfortable, the three related learning activities for this topic are activated as well. Each learning activity has a dedicated learning environment that includes a note-taking tool assigned. This allows the learner to take notes while performing a learning activity. When the learner has taken notes related to the active building, the biography of its architect and a related residential house from the same architect are activated. As soon as a learner has completed one of the three tracks a reflection activity for this track becomes available. This reflection activity is an assignment and includes all notes that have been taken in relation to the track. As soon as the learner is satisfied with the results of the reflection assignment the learner can submit the results. If all reflection assignments are submitted, the UoL is completed.

This educational design can be based entirely on personal-properties. Besides personal-properties for storing notes and choices, the UoL has some properties that are required for sequencing. These properties are used to compensate the "completed" flag: instead of completing a learning activity only a property 'task-complete-ID' is set, where ID is replaced by the mnemonic name of the related activity. For the learning activities with a note-taking environment, this flag is modelled through a condition that checks if the learner has taken a note. The task-complete-property is also used for the reflection activities to identify if the reflection assignment of this activity has been submitted. The properties are set and notes are stored by embedding global-elements in activity descriptions and in the note-taking tool. The difference is transparent to the learners, because in both variations the learners mark that they have finished an activity.

A set of 20 conditions handles the sequencing within the UoL. Most of the conditions are simple tests, on the task-complete-properties or if a note has taken. The more complex conditions are used to test if one of the main three tracks or the entire UoL has been finished. All conditions are required for making the next learning activities available to the learner by showing them. 


\section{Comparison and gap analysis}

The previous section outlined the concepts for adaptive educational designs using IMS LD Level A and Level B. The first variation of the UoL was modelled using entirely Level A concepts. The example shows that it is possible to include elements of personalization into educational designs and to provide learners with (limited) control based on basic orchestration rules. The second variation of the educational design utilizes primarily IMS LD Level B concepts for defining the orchestration script. As reported by previous research the available semantic structure provides a powerful instrument for outlining the information of user models that are relevant for orchestration process and to model learning activities with great freedom for the learners.

The main difference between the two variants is that activity-structures are not used in the second UoL. The main problem with activity-structures within IMS LD Level B designs is that selection and sequencing conditions of the structure rely on the completion state of the activities. This hinders learners to retry a learning activity, because once a learning activity has completed it cannot be uncompleted and thus not repeated. The second variation of the UoL discussed in this paper, allows learners to move back to previous learning activities if they realize that their notes are insufficient for mastering the reflection activity. In order to achieve this it is required that a learning activity cannot be completed in the sense of the IMS LD specification. Consequently, it is not possible to combine the two variants into a single UoL if both approaches use the same learning activities. In order to work around this problem, it would be necessary to "clone" the original learning activity so the cloned learning activity uses the same data items and environments as the original activity. However, this way of duplicating learning activities is not supported by the ReCourse editor. Moreover, this technique is prone to errors: e.g. if the instructional designer decides to replace items or environments of one of the learning activity, the other learning activity would not be aware of these changes.

From an orchestration perspective IMS LD includes all aspects for prearranging a learning scenario. For defining orchestration rules, IMS LD offers features for enabling instructional designers to define how a UoL can be personalized. The perspective of these rules is mainly task-centred with presentation related aspects. This has consequences for the orchestration related to roles and learning environment.

Roles in IMS LD are only defined as grouping mechanisms for the participants in a UoL. Many aspects related to the orchestration of roles are explicitly considered as external to the specification. Therefore, the specification is lacking of semantics for modelling role assignment and role structures. Consequently, it is not possible to model explicit rules for assigning learners to different roles based on the results of an assessment, so they can follow tailored learning paths. In IMS LD this can be achieved only implicitly by setting up a support activity.

Environments are used to connect learning activities with the learning tools that are required for an activity such as knowledge resources or educational services. IMS LD considers this relation as unidirectional, which means that the learning activity determines what environments are available. From an orchestration perspective the relation between activities and their environment appears bidirectional. This implies 
that being in an environment can also determine possible learning activities. Such behaviour can be partly modelled with special conditions and pseudo learning activities. Additionally, such a workaround would require interaction elements. Alternatively, external services might update "global" properties, which would trigger related conditions in a UoL. However, this second workaround is partly implicit for the orchestration process and it requires implementation of specific knowledge about the underlying property management system.

\section{Conclusion and future work}

This paper analysed the relation between the concepts of IMS LD and orchestrating learning in order to identify approaches and gaps for creating orchestration scripts. The research integrates perspectives from the research on adaptive systems and instructional design theory. Based on analyzing the previous research four fundamental aspects for orchestrating learning were identified. Based on this background a UoL for studying "Modern Architecture: Skyscrapers and Residential Homes" has been modelled in two variants with IMS LD Level A and Level B features for the integration of personalization aspects. It has been shown that even with IMS LD Level A it is possible to define UoLs with limited personalization features. For more flexible orchestration scripts IMS LD Level B offers richer semantics that allows the integration of basic user-modelling approaches. The variations of the UoL demonstrate possible personalization features. The gap analysis extended this view to those aspects of orchestrating learning that could not get modelled in IMS LD. The gap analysis indicates that IMS LD has a primarily taskcentred approach to orchestration. Role- or environmental-centred orchestration can be only achieved with complex workarounds or have to be modelled implicitly.

The present research focuses on personalisation and adaptation aspects for orchestrating learning using the IMS LD specification. Future research will carry on these findings and analyses the identification of possible semantic extensions that allow simpler and more explicit orchestration scripts that can be based on IMS LD.

Acknowledgements: The research presented in this paper has been partly sponsored by the GRAPPLE project (www.grapple-project.org) funded by the European Commission's $7^{\text {th }}$ Framework Programme and iCOPER best-practice network (www.icoper.org) within the European Commission's eContentPlus programme.

\section{References}

[1] IMS Global Learning Consortium: Learning Design Specification. Technical specification, IMS Global Learning Consortium (2003) http://www.imsglobal.org/learningdesign/

[2] Jeffery, A. \& Currier, S.: What Is ... IMS Learning Design? Cetis, Standards Briefings Series, JISC (2003) http://zope.cetis.ac.uk/lib/media/WhatIsLD_web.pdf 
[3] Koper, R. \& Tattersall, C.: Learning Design: A Handbook on Modelling and Delivering Networked Education and Training. Springer, Heidelberg (2005)

[4] Koper, R., \& Specht, M.: TEN-Competence: Life-Long Competence Development and Learning. In M-A. Cicilia (ed.), Competencies in Organizational e-learning: concepts and tools. Hershey: IGI-Global, 234-252 (2008)

[5] Sharples, P., Griffiths, D., \& Scott, W.: Using Widgets to Provide Portable Services for IMS Learning Design. In R. Koper, K. Stefanov \& D. Dicheva (eds.) Stimulating Personal Development and Knowledge Sharing, pp. 57-60. October, 30-31, 2008, Sofia, Bulgaria (2008)

[6] Sutherland, R. \& Joubert, M.: D1.1: The STELLAR Vision and Strategy Statement. Project Report. Stellar project. Unpublished Report, Stellar NoE (2010)

[7] Berlanga, A. J., \& Gracía, F. J.: IMS LD reusable elements for adaptive learning designs. Journal of Interactive Media in Education, 2005(11), pp. 1-16 (2005) http://jime.open.ac.ul/2005/11

[8] Burgos, D., Tattersall, C., \& Koper, R.: How to represent adaptation in eLearning with IMS Learning Design. Interactive Learning Environments, 15(2), pp. 161-170 (2007)

[9] Specht, M. \& Burgos, D.: Implementing Adaptive Educational Methods with IMS Learning Design. In Proceedings of the ADALE Workshop at the AH2006 Conference (2006) http://hdl.handle.net/1820/718

[10] Aroyo, L., Dolog, P., Houben, G., Kravcik, M., Naeve, A., Nilsson, M., et al.: Interoperability in Personalized Adaptive Learning. Educational Technology \& Society, 9(2), pp. 4-18 (2006)

[11] Verpoorten, D., Glahn, C., Kravcik, M., Ternier, S., \& Specht, M.: Personalisation of Learning in Virtual Learning Environments. In U. Cress, V. Dimitrova \& M. Specht (eds.), Learning in the Synergy of Multiple Disciplines, LNCS, vol. 5794, pp. 52-66. Springer, Heidelberg (2009)

[12] Dron, J.: Control and Constraint in E-Learning: Choosing When to Choose. IGI Publishing, Hershey, PA (2007)

[13] Goodyear, P., \& Yang, D.: Patterns and pattern languages in educational design. In L. Lockyer, S. Bennett, S. Agostinho \& B. Harper (eds.), Handbook of Research on Learning Design and Learning Objects: Issues, Applications and Technologies, pp. 167187. IGI Global, Hershey PA (2009)

[14] Dillenbourg, P.: Integrating technologies into educational ecosystems. Distance Education, 29(2), pp. 127-140 (2008)

[15] Brusilovsky, P.: Adaptive hypermedia. User Modeling and User-Adapted Interaction, 11, pp. 87-110 (2001)

[16] Koper, R.: Current Research in Learning Design. Educational Technology \& Society, 9 (1), pp. 13-22 (2005)

[17] IMS Global Learning Consortium: IMS Learning Design Information Model. Technical specification, IMS Global Learning Consortium (2003) http://www.imsglobal.org/learningdesign/ldv1p0/imsld_infov1p0.html

[18] Paramythis, A., \& Loidl-Reisinger, S.: Adaptive learning environments and e-learning standards. Electronic Journal of eLearning, EJEL, 2(1), pp. 182-194 (2004) http://www .ejel.org/volume-2/vol2-issue1/issue1-art11-paramythis.pdf

[19] Van Rosmalen, P., Vogten, H., van Es, R., Passier, H., Poelmans, P., \& Koper, R.: Authoring a full life cycle model in standards-based, adaptive e-learning. Educational Technology \& Society, 9 (1), pp. $72-83$ (2006)

[20] Harrigan, M. \& Wade, V.: Towards a conceptual and service-based adaptation model. In Proceedings of the International Workshop on Dynamic and Adaptive Hypertext: Generic Frameworks, Approaches and Techniques (2009) 
16 Marion R. Gruber, Christian Glahn, Marcus Specht \& Rob Koper

[21] Van der Sluijs, K. \& Höver, K.M.: Integrating adaptive functionality in a LMS. International Journal of Emerging Technologies in Learning (iJET), 4(4), pp. 46-50 (2009)

[22] Vogten, H.: Design and implementation strategies for IMS Learning Design. Doctoral Thesis. CELSTEC, Open University in The Netherlands, Heerlen, The Netherlands (2008)

[23] GRAPPLE project: Project summary. (2009) http://www.grapple-project.org/summary

[24] Van Merriënboer, J.J.G., Clark, R.E., de Croock, M.B.M.: Blueprints for Complex Learning: The 4C/ID-Model. Educational Technology, Research and Development, 50(4), pp. 39-64 (2002)

[25] Kobsa, A. (2001). Generic User Modeling Systems. User Modeling and User-Adapted Interaction, 11(1-2), 49-63.

[26] Gruber, M. R. \& Glahn, C.: IMS-LD Modern Architecture: Skyscrapers and Residential Homes Level A. IMS content package, Heerlen, The Netherlands (2010) http://hdl.handle.net/1820/2550

[27] Gruber, M. R. \& Glahn, C.: IMS-LD Modern Architecture: Skyscrapers and Residential Homes Level B. IMS content package, Heerlen, The Netherlands (2010) http://hdl.handle.net/1820/2551

[28] Stefaner, M. et al.: MACE. Joint Deliverable JD11: Evaluation of the MACE system. Project report (2009) http://dspace.ou.nl/handle/1820/2193

[29] Gruber, M. R., Börner, D. \& Ternier, S.: MACE for Educators. (2009). http://www.maceproject.eu/index.php?-option=com_content $\&$-task=blogsection\&id=6\&Itemid=87

[30] Beauvoir, P., Griffith, D., \& Sharples, P.: Learning Design Authoring tools in the TENCompetence Project. In R. Koper (ed.) Learning Network Services for Professional Development, pp. 379-387. Springer, Heidelberg (2009)

[31] TENCompetence Foundation: TENCompetence Learning Design Services for Coppercore Service Integration. TENCompetence Foundation (2009) http://tencompetence-project.bolton.ac.uk/-ldruntime/-index.html

[32] European Parliament \& Council of the European Union: Directive 2005/36/EC on the recognition of professional qualifications. European Union, Brussels and Strasbourg (2005)

[33] Council of the European Union: Council Directive on the mutual recognition of diplomas, certificate and other evidence of formal qualifications in architecture, including measures to facilitate the effective exercise of the right of establishment and freedom to provide services (85/384/EEC). Strasbourg: European Union, Strasbourg (1985) 